\title{
Comparing power imagery in TATs written by hand or on the computer
}

\author{
VIRGINIA BLANKENSHIP and ANDREW L. ZOOTA \\ Northern Arizona University, Flagstaff, Arizona
}

\begin{abstract}
Two barriers to the use of the Thematic Apperception Test (TAT) in motivation research were addressed: its low internal consistency and its time-consuming coding system. Sixty males and 60 females wrote five stories to TAT pictures either on the computer or by hand. Half of each group were timed and half untimed. The writing of stories was guided by four sets of questions, and stories were coded for need for power (n Pow) by the corresponding four paragraphs. Cronbach's alpha for the five stories was .46; for the 20 paragraphs, Cronbach's alpha was .65. We conclude that, to the extent that measuring internal consistency is appropriate for a thought-sampling instrument like the TAT, internal consistency should be calculated by paragraphs. Significantly more words were produced in the untimed condition, but $n$ Pow did not differ by gender, hand-written versus computer-written, or timed versus untimed conditions. The five pictures elicited significantly different amounts of $n$ Pow. It is recommended that researchers who give the TAT on the computer use the untimed condition. Suggestions are made for increasing the scoring validity and for using the computer to decrease the time required for human coders.
\end{abstract}

The Thematic Apperception Test (TAT) ${ }^{1}$ has been used in research on achievement, affiliation, power, and intimacy (among others), and coding schemes are available to score imagery in each of these motives (Smith, 1992). We focused on power motivation in this study of the effects of computer writing on projective content or thought samples because we believed that power imagery might be the most susceptible to augmentation by the computer situation, although achievement imagery might also be affected. ${ }^{2}$ Power imagery is coded when a story depicts someone acting in a way that expresses power, arousing strong positive or negative emotions, or showing concern for reputation or position. Power-oriented actions include attacks, insults, and seductions, giving help or advice that is not solicited, controlling someone else's life, trying to influence, bribe, or persuade, and trying to impress others (Winter, 1992, pp. 312-315). We assumed that if the computer could affect any motive, power was the most likely. This is based on the idea of the computer as empowering, as a device that can arouse strong emotions (e.g., frustration), and as a prestigious possession (Winter, 1973).

Two barriers to the use of the TAT to measure power imagery in motivation research have been its apparent

This research was supported in part by NSF Research Experience for Undergraduates Award BIR-9300595. We wish to thank Stacy Allison, Pamella Cordova, Tad Gary, Cynthia Gomes, Matt Herzberg, Margaret Kalamaras, Amanda Kapp, and Kathy Kunkel for helping us code TAT stories; Nisha Waghray and Jeni Fletcher for organizing data; and Jennifer Seiffer and Julie Gillette for transcribing stories. Bruce Dudek advised us on data analysis, and Randi Reppen edited the manuscript. We thank Tilly Houtmans, Charles P. Smith, and Ronald T. Kellogg for their comments on an earlier draft of this paper. Contact V. Blankenship at P.O. Box 15106, Department of Psychology, Northern Arizona University, Flagstaff, AZ 86011 (e-mail: virginia.blankenship@nau.edu). low internal consistency and its time-consuming coding system. The first criticism, that it lacks internal consistency, may be unfair. Traditional test theory assumes that each item on a test contributes to the "true score" and that internal consistency is essential. Applying this model to the TAT forces the researcher to consider each picture and its corresponding story as one item on the test. TAT stories are elicited, however, with four sets of questions that guide the writing of each story. At the very least, therefore, each story can be conceptualized as four items. We will argue that computing the internal consistency of the TAT is more appropriate if the stories are broken down into sections corresponding to these questions.

Traditionally, in research, TAT stories have been hand written and timed, with subjects given 4-6 min to write each story. Reading and coding these stories is time consuming; but, if stories could be written on the computer and content analysis performed on the computer, this second obstacle might be overcome. However, would the different modes of composition affect the power motivation of the person? One purpose of this study, therefore, was to compare TATs that were hand written and computer written, in order to see whether systematic differences in amount of power imagery would be present. Such a comparison has not been done before.

One problem with transferring the TAT to the computer is that subjects will vary a great deal in their ability to type. We were concerned, therefore, that regardless of the amount of power motivation people have, their production of power imagery in a timed situation would be affected by their typing ability, adding noise to the detection of individual differences in power motivation. To investigate this possibility, we compared timed versus untimed conditions in order to see whether subjects would 
produce more words and more power imagery if they were given more time to write stories.

\section{What the TAT Measures}

The TAT was developed to get at needs that were assumed to be latent and available when people projected those needs into the characters in fantasy stories written to ambiguous pictures (Morgan \& Murray, 1935; Murray, 1938). McClelland, Atkinson, Clark, and Lowell (1953) developed a method for scoring achievement imagery in TAT stories, and methods for the content analysis of several needs are now available (see Smith, 1992). McClelland, Koestner, and Weinberger (1989) have distinguished between self-attributed and implicit motives, the former being measured by self-report questionnaires and the latter through projective measures, such as the TAT. They propose that implicit motives develop early in childhood in response to affective experiences. People may not be fully aware of these motives and are unable to express implicit motives directly. Thus the TAT is one of the methods used to measure them. Self-attributed motives develop in later childhood and are available to people when they are asked to respond to a questionnaire item.

DeCharms (1992) refers to verbal materials elicited in response to ambiguous cues, such as pictures and suggestions about story topics ("A man is looking at his dog") as thought samples. He conceptualizes thought sampling as "a nonselfconscious description of the way a person experiences her world" (p. 326). Atkinson, Bongort, and Price (1977) consider the imagery in a TAT story as a reflection of time spent thinking about one motive in the context of all the other motives that the person might be thinking about in the testing session. Rather than seeing the story as a projection of one's motives onto the characters, they consider writing the story to be an action that directly reflects the underlying motives of the individual.

\section{Criticisms of the TAT}

Whether the TAT is viewed as a projective measure, a thought sample, or a reflection of time spent thinking about motives, researchers have questioned its reliability as a measure of individual differences. Murstein (1965) stated that "projective techniques have lower reliabilities than multiple-choice paper-and-pencil tests because, in addition to the usual sources of error, they add new ones. These include ... scorer reliability, the influence of a response on succeeding responses, ... and the ofttimes peculiar distributions of scores" (p.189).

Jensen (1959) identified two sources of error variance: test error and scoring error. According to Jensen there are a number of extratest factors that affect reliability, including "(a) examiner differences and differences in conditions under which projective protocols are obtained, (b) differences in 'ability' of scorers or interpreters of the protocols, (c) the range of the personality factors measured by the test in a particular sample, (d) the quantity of projective material obtained from the S (e.g., length of TAT stories)." Fineman (1977) concluded that the TAT is "too short to yield sufficient construct variance to overcome its error variance."

Entwisle (1972) asserted that the TAT has low reliability, revealed in its lack of internal consistency. In her review of the literature, Entwisle found the reliability to be uniformly "in the range of .30 to .40" (p. 389), too low to allow adequate predictive validity, according to traditional test theory.

Nunnally (1978) advises that "The primary way to make tests more reliable is to make them longer" (p. 243). That is, the more the items on a test, the higher its reliability. The internal consistency of the TAT has been based on the number of pictures used, each picture counting as one test item. Actually, the TAT stories are elicited by four separate sets of questions for each picture (e.g., What is happening? Who are the persons?) We have conceptualized our five-picture TAT as a 20 -item test and computed the reliability using 20 items ( 5 stories $\times 4$ questions per story). Power imagery was coded by paragraphs; that is, each of the subcategories was counted as a response to one of the four questions. We believe that this method provides a more realistic estimate of the reliability of the TAT.

\section{Responses to Criticisms}

Atkinson et al. (1977) used the dynamics of action theory of motivation (Atkinson \& Birch, 1970) to explore the problem of internal consistency in projective tests. One of the main inferences from the dynamics of action is that the motive score (e.g., need for achievement, or $\mathrm{n}$ Ach; need for power, $\mathrm{n}$ Pow) does not measure the strength of the motive; rather, it measures the strength of the motive in comparison with all other motives. Within traditional test theory, each story is treated as if it were a separate test of a person's need. It assumes that the obtained score for the story is the "true score" \pm error. The dynamics of action, on the other hand, emphasize continuity in the motivational task and conceptualize the motive score as a function of time spent thinking about that motive. Any factor that could affect the time spent thinking about other motivational tendencies, and not the one that is being tested, would cause a decrease in internal consistency. In addition, thinking and writing about power imagery, for example, decreases the tendency to continue writing about power. Therefore, expressed $n$ Pow in one story can decrease the tendency to write about power in the next story, thereby decreasing internal consistency.

In her overall review of the TAT, Vane (1981) reiterated that to be able to obtain high internal consistency, it would be necessary for the motivation being tested to be expressed in each story. Vane concluded that "of course, this is not the case" (p. 332). She noted that people, as well as the pictures used, are multidimensional, causing each response from the subject to be different for each story. McClelland (1985) agrees that there is sufficient evidence to expect the motive score from one story not to be highly correlated with the motive score for the next story.

Smith (1992) has suggested that the reliability of the TAT can be increased if pictures are sampled broadly from 
the domain of interest (power) and provide a good distribution of scores, if enough stories are written to provide adequate content for coding, and if coding errors are reduced. Haber and Alpert (1958) reported that more reliable measurements of individual differences in response to motivational cues were elicited with the use of strongly cued pictures rather than weakly cued pictures. Smith (1992) argues that pictures that elicit an intermediate to high percentage of imagery produce a more desirable distribution of scores. The pictures in this study were selected from previous research and had been shown to elicit an intermediate to high percentage of imagery (McClelland, 1975; Smith, 1992; Winter, 1973).

Atkinson (1982) has proposed that the use of more than four pictures in one testing session can reduce reliability, owing to factors such as subject fatigue. Smith (1992) has recommended that six stories be written. As a compromise between these positions, five picture cues were used for this study. Coding errors were reduced by having each story coded for $n$ Pow twice, by two different coders, and by having a group of two additional coders eliminate discrepancies between the code produced by the two original coders.

\section{Hand Versus Computer Writing}

Since the computer was first introduced, it has been viewed as an important tool in education, especially in helping students learn to write. Early research focused on the computer as a transcription tool, with subjects writing first with pen or pencil and then entering the text on a computer (Hawisher, 1986). In a subsequent review of 16 studies of computer composition, Hawisher (1988) reported that the majority of research found an increase in the number of words produced by subjects in the computer-written conditions. She proposed that "longer texts might well be a result of the ease with which even young students can write with word processing and perhaps indicates increased motivation for students working with computers" (p. 13). Another common finding, cited by Hawisher, was the improvement in quality shown by basic writers in computer-written conditions. In a metaanalysis of 20 studies measuring writing improvement, Bangert-Drowns (1993) found reliably greater improvement for the computer-written condition, although the effect size was "fairly small" (p. 87). Nichols (1986) found that writers produced more words in the word processing sessions, even though they took less time.

The instructions for the TAT direct the writer not to worry about errors in grammar or spelling. Subjects are encouraged to write freely, with no planning or revising. Rosenbluth and Reed (1992) have shown that the fluency of writing increases with the use of computers, perhaps because less time is spent planning when computers are being used. In her research with college students, Haas (1989) found that writers spent significantly less time planning when at the computer. In a comparison of computer-based writing and writing by hand, Kellogg and Mueller (1993) looked at the allocation of attention dur- ing the writing process. They focused on planning, translating, and reviewing. Because subjects writing TAT stories are encouraged to write quickly "whatever story comes to mind when you look at a picture," we assume that most of their time is devoted to translating (generating the story), as opposed to planning and reviewing. Kellogg and Mueller found that subjects in the two conditions did not differ in the amount of time that they spent translating.

Directions for the TAT ask that participants "write your first impressions" (Atkinson, 1958, p. 837). Decreasing the degree to which subjects mentally edit their writing enables execution to occur rapidly, just as the TAT instructions ask. Brown, McDonald, Brown, and Carr (1988) have shown that when participants were asked to stress speed over accuracy, accuracy of content did not decline. If power imagery is viewed as an accurate reflection of power motivation resulting from a person's world view, the instructions to "work rapidly" should not cause the amount of power imagery elicited by the picture to be reduced.

\section{Time Pressure}

The pressure of time is a pervasive factor in human performance. Whether there is a designated time limit or a self-assigned deadline, time plays an important role. Rindler (1979) classified tests as either speed instruments or power instruments, depending on how time affects a person's score. If a test is classified as a complete speed test, the items are so easy that the number of problems attempted is the same as the number correct. A test is classified as a power test to the extent that the items are so difficult that the number correct out of the number attempted is not necessarily related to the rate of work. Given these definitions, the TAT may be both a speed instrument and a power instrument because the amount of motivational imagery expressed in the stories may be a function both of time allowed for writing and the "difficulty" of the pictures (i.e., how strong the cues are for eliciting "correct" imagery subcategories).

Time spent on various activities is the focus of the Atkinson and Birch (1970) dynamics of action theory. In a testing situation, it is assumed that the person is already actively participating in two senses before the stimulus is presented. Atkinson et al. (1977) point out that the individual is already doing something when the scientific observation begins. The person is also motivated to do many other things besides what the experimenter has in mind. In a typical TAT experiment, subjects may be thinking about other things besides the stimulus picture presented to them. By reading the instructions to the subject, the experimenter is steering the subject's attention to the task at hand, which is to begin writing. The demand characteristics are so strong that most subjects start writing when given the signal, even though the subjects may be thinking about something other than the activity at hand.

If the picture is a strong cue for the motive being tested, such as $n$ Pow, and if the person has a high $n$ Pow, then the story should contain a lot of power imagery. If the person is inhibited from expressing this need, perhaps because 
he/she thinks power is negative, the dynamics of action theory predicts that the expression of power imagery will be delayed until the inhibition has been dissipated. According to the dynamics of action theory, overcoming this inhibition takes time. Therefore, time limits might expire before the subject has a chance to express a motive that is high but that is also subject to inhibition. In an untimed condition, subjects would have more time to overcome the inhibition. We would therefore expect more power imagery to be expressed in the untimed condition, even when the scores are adjusted for the number of words.

Specifically, we predicted that the internal consistency of the five-story TAT would be greater when conceptualized as a 20 -item test than when conceptualized as a 5item test. It was expected that stories written on the computer would have more power imagery than would stories written by hand and that stories written in the untimed conditions would have more power imagery than would stories written in the timed conditions. We expected that stories written in the untimed conditions would be longer than stories written in the timed conditions and that there would be a positive correlation between the number of words in a story and the amount of power imagery expressed.

\section{METHOD}

\section{Subjects}

The subjects were 145 students ( 60 males, 85 females) enrolled in introductory psychology courses at Northern Arizona University who volunteered to participate in an experiment entitled "Story Writing" to earn optional extra credit in their courses. Because there were more females than males who volunteered, 25 female subjects were randomly dropped to create an equal number of males $(n=60)$ and females $(n=60)$. Subjects ranged in age from 18 to 50 , with a median age of 19 years.

\section{Design}

The experiment was a 2 (hand-written vs. computer-written) by 2 (timed vs. untimed) $\times 2$ (female vs. male) between-subjects design. All subjects wrote TAT stories to five pictures. The dependent variables were the amount of power imagery contained in the stories and the number of words written.

\section{Apparatus}

The research version of the TAT (Murray, 1938; Smith, 1992) was used to elicit stories that were coded for power imagery using Winter's method (Winter, 1973, 1992). Five pictures were used as power cues. Three of the pictures came from Smith (1992): Pictures 3 ("Couple on bench by river"), 4 ("Two women in lab coats in laboratory"), and 5 ("Trapeze artists"; pp. 635-637). A picture of a man and woman in a restaurant listening to a guitar player was taken from McClelland $(1975$, p. 386). Winter provided a picture of a group of men in military uniforms studying a map, one of the pictures that had been used in developing Winter's coding scheme (1973, pp. 274-276). The pictures were scanned into the computer with Adobe Photoshop. The laboratory picture was edited to make the gender of the woman in the background more ambiguous. (Most subjects wrote stories to the laboratory picture with a male character and a female character.) The restaurant picture was edited to remove the cigarette from the woman's hand. The computer and paper versions of the pictures were identical; the computer versions were imported to Authorware Professional, and the paper versions were printed directly from Adobe Photoshop. The pictures were all $5 \mathrm{~cm}$ high and ranged from 6.5 to $8 \mathrm{~cm}$ wide.

The five pictures were presented to each of the 120 subjects in a unique order. The 120 possible sequences were assigned randomly to the four conditions, with the constraint that six sequences beginning with each of the five pictures in the first ordinal position were assigned to each condition $(6 \times 5=30$, the number of subjects in each condition).

Half of the subjects wrote stories by hand, and the other half wrote stories on a computer. On the paper versions, the pictures were centered at the top of the page and the four probes: " 1 . What is happening? Who are the persons?" "2. What has led up to this situation? That is, what has happened in the past?" "3. What is being thought? What is wanted? By whom?" and "4. What will happen? What will be done?" were printed approximately $4 \mathrm{~cm}$ apart down the rest of the page. The computer program that presented the pictures and captured the stories was written with Authorware Professional. The pictures appeared in the top right-hand corner, and the probes appeared one at a time in the upper left-hand part of the screen. A new input window (with the same picture) appeared with each of the four probes. The ongoing story appeared in the lower right-hand part of the screen, under the picture, so that the subjects could see what they had already written, although they could not change it. When a new picture cue appeared, the input window and the output window containing the ongoing story were both cleared. Stories were written to the hard drive as they were completed.

All subjects were tested in a computer laboratory containing 30 Macintosh LCIII computers. In both the hand-written and the computer-written conditions, the computers were uncovered and turned on.

\section{Procedure}

Thirty subjects ( 15 males, 15 females) were assigned by gender to each of four conditions: hand-written/timed (HT), hand-written' untimed (HU), computer-written/timed (CT), and computer-written/ untimed (CU). The subjects were run in groups ranging from 2 to 30 , and all the subjects in a given group were randomly assigned to one of the four conditions. In both timed conditions, the subjects were given 5 min to write each story. The subjects first read and signed consent forms. In the HT condition, the senior author read the directions with the subjects and then paced them through writing the stories by suggesting at the end of each 75-sec interval, "You should be moving to the next section." At the end of $5 \mathrm{~min}$, she said, "Stop writing." In the CT condition, at the end of $75 \mathrm{sec}$, there was a soft beep, the input window cleared, and the story, as currently written, appeared in the output window. If the subject completed responding to one of the four probes before the $75 \mathrm{sec}$ were up, the subject could move to the next probe and received credit for the unused time. Just below the input window the computer printed the number of seconds remaining. In both the $\mathrm{HU}$ and the CU conditions, the subjects could write for as long as they wished.

\section{Coding}

Two groups of five coders studied Winter's (1973) materials and reached expert levels of coding; all 10 achieved .87 to .98 agreement with expert-coded stories. The hand-written stories were transcribed and printed in a format exactly like that for the computerwritten stories. Thus the coders were blind to the condition under which the stories had been written. Each story was coded by two different coders. Within the constraint that a story could not be assigned to the same person twice, the stories were assigned randomly to the coders. There was agreement between the two coders on presence or absence of power imagery in $72 \%$ of the 600 stories. Agreement among coders was greatest for the military stories $(83 \%)$ and lowest for the trapeze stories $(65 \%)$. If both coders found no imagery, the stories were not processed further. If one coder scored imagery and the other did not, a two-person committee (neither of 
Table 1

Repeated Measures MANOVA of $n$ Pow Coded in Five TAT Pictures $(n=120)$ Source

\begin{tabular}{|c|c|c|c|c|}
\hline Source & $d f$ & $M S$ & $F$ & $p$ \\
\hline \multicolumn{5}{|c|}{ Between Subjects } \\
\hline Gender (G) & 1 & .04 & .01 & .94 \\
\hline Hand versus computer written $(\mathrm{H} / \mathrm{C})$ & 1 & .20 & .03 & .87 \\
\hline Timed versus untimed $(T / U)$ & 1 & .28 & .04 & .84 \\
\hline $\mathrm{G} \times \mathrm{H} / \mathrm{C}$ & l & .48 & .07 & .79 \\
\hline $\mathrm{G} \times \mathrm{T} / \mathrm{U}$ & 1 & 1.04 & .15 & .70 \\
\hline $\mathrm{G} \times \mathrm{H} / \mathrm{C} \times \mathrm{T} / \mathrm{U}$ & I & 3.37 & .48 & .49 \\
\hline Within cells & 112 & 7.02 & & \\
\hline \multicolumn{5}{|c|}{ Within Subjects } \\
\hline Pictures $(\mathrm{P})$ & 4 & 91.65 & 25.59 & .00 \\
\hline$G \times P$ & 4 & 2.29 & .64 & .64 \\
\hline $\mathrm{H} / \mathrm{C} \times \mathrm{P}$ & 4 & 3.21 & .90 & .47 \\
\hline $\mathrm{T} U \times \mathrm{P}$ & 4 & 11.46 & 3.20 & .01 \\
\hline $\mathrm{G} \times \mathrm{H} / \mathrm{C} \times \mathrm{P}$ & 4 & 4.39 & 1.23 & .30 \\
\hline $\mathrm{G} \times \mathrm{T} / \mathrm{U} \times \mathrm{P}$ & 4 & .70 & .19 & .94 \\
\hline $\mathrm{H} / \mathrm{C} \times \mathrm{T} / \mathrm{U} \times \mathrm{P}$ & 4 & 3.33 & .93 & .45 \\
\hline $\mathrm{G} \times \mathrm{H} / \mathrm{C} \times \mathrm{T} / \mathrm{U} \times \mathrm{P}$ & 4 & 6.93 & 1.93 & .10 \\
\hline Within cells & 448 & 3.58 & & \\
\hline
\end{tabular}

whom coded the story originally) reconciled the discrepancy. In all cases where power imagery was coded, the two-person committee verified the location of the phrase which was the basis for coding power imagery (Categories 1a-le, 2, or 3) and all of the subcategories (Pa+, Pa-, etc.; see Winter, 1973, or Smith, 1992).

An example of a story and the way it was coded by paragraphs is presented below:

1. The General $(\mathrm{Pa}+)$ has given specific orders to his soldiers but they are not following them. There seems to be some kind of meeting. $\mathrm{n}$ Pow $=1$

2. The men used to be happy under his command but they have noticed him acting a little strange. Irrational. They don't believe he is fit to command them. now $=0$

3. The general is scared. Why are his men doing this to him? He feels angry and betrayed. (G-) He pulls his gun on them (I) and says "The first soldier to stand in my way as commander will die." (1a). $\mathrm{n}$ Pow $=3$

4. The soldiers manage to get the gun away from the general and restrain him (Eff). And so sadly ends the career of a highly decorated, although highly disturbed. general $(\mathrm{Pa}-)$. $\mathrm{n}$ Pow $=2$

When coding was complete, a $120 \times 20$ matrix was constructed; for each of the 120 subjects, 20 numbers were entered, indicating the number of times power or a subcategory of power was found in each of the four paragraphs (in response to each of the four probes). Following Winter (1973, 1992), each category and subcategory was scored just once in a given story. Thus we had complete data, so that the stories could be analyzed as 20 items (four sets of questions for each of the five stories) or summed and analyzed as 5 items. For example, for the story above, $1,0,3$, and 2 were entered as data for the 20 -item test and summed to 6 for the 5 -item test. The number of words in each of the stories was also calculated and entered as data

\section{RESULTS}

\section{Internal Consistency}

Reliability coefficients were determined two different ways. Based on 5 scores (one for each story) Cronbach's alpha was .46. Based on 20 scores (four questions elicited each of five stories: $4 \times 5=20$ ), Cronbach's alpha was .65. Internal consistency computed on 20 paragraphs was substantially higher than internal consistency computed on five stories, thus supporting the first hypothesis.

\section{Power Imagery}

A multivariate analysis of variance (MANOVA) was performed, using the amount of power imagery in each story as the dependent variable (see Table 1). The independent variables were gender (males vs. females) and experimental conditions (hand written vs. computer written crossed with timed vs. untimed). The five story cues elicited significantly different amounts of power imagery (see Table 2), with the military picture resulting in stories with the largest amount of power imagery. The laboratory, restaurant, and trapeze pictures elicited an intermediate amount of $\mathrm{n}$ Pow, and the bridge picture elicited a low amount of $n$ Pow. This effect was found even when the number of words in each story was used as a covariate to control for story length.

A significant picture by timed versus untimed interaction was found. Subjects wrote more power imagery in response to the restaurant picture in the untimed condition than in the timed condition. In response to the trapeze picture, however, they wrote more power imagery in the timed condition than in the untimed condition.

No significant differences were found in the amount of power imagery between males and females, between timed and untimed conditions, or between hand-written and computer-written conditions (see Table 1), lending no support to the second and third hypotheses. We summed power imagery across the five pictures, and the grand mean was 10.54 with standard deviation of 5.79 , kurtosis of $-.75(S E=.44)$, and skewness of $.046(S E=.22)$. For males, the mean was $10.50(S D=6.13)$, and for females, $10.58(S D=5.48)$. Total power imagery in the handwritten condition was $10.63(S D=6.04)$ and 10.45 in the computer-written condition $(S D=5.58)$. In the timed condition, total power imagery was $10.43(S D=5.44)$ and $10.65(S D=6.16)$ in the untimed condition.

\section{Story Length}

A second repeated measures (five stories) MANOVA was performed, with number of words as the dependent variable and with gender, hand written versus computer written, and timed versus untimed as independent variables. Across all conditions, female subjects produced more words $(M=125.46$ words, $S D=43.22)$ than did male subjects $(M=107.56$ words, $S D=35.11)[F(1,112)=$

\section{Table 2}

Mean $n$ Pow $\times$ Picture $\times$ Timed

Versus Untimed Conditions ( $n=120)$

\begin{tabular}{|c|c|c|c|c|c|c|}
\hline \multirow[b]{2}{*}{ Picture } & \multicolumn{2}{|c|}{ Timed } & \multicolumn{2}{|c|}{ Untimed } & \multicolumn{2}{|c|}{ Combined } \\
\hline & $M$ & $S D$ & $M$ & $S D$ & $M$ & $S D$ \\
\hline Military & 3.65 & 1.83 & 3.40 & 2.10 & 3.53 & 1.97 \\
\hline Laboratory & 2.13 & 2.17 & 2.20 & 2.13 & 2.17 & 2.14 \\
\hline Restaurant & 1.40 & 2.01 & 2.38 & 2.43 & 1.89 & 2.27 \\
\hline Trapeze & 2.15 & 2.26 & 1.45 & 1.92 & 1.80 & 2.12 \\
\hline Bridge & 1.10 & 1.72 & 1.22 & 1.85 & 1.16 & 1.78 \\
\hline
\end{tabular}


$7.09, p<.01]$. As hypothesized, more words were produced in the untimed conditions $(M=127.61$ words, $S D=$ 46.19) than in the timed conditions $(M=105.41$ words, $S D=29.65)[F(1,112)=10.92, p=.001]$.

In addition, a gender by hand written versus computer written interaction was found $[F(1,112)=5.96, p<.02]$. Males did not differ in their production of words on the computer $(M=104.27, S D=33.78)$ as compared with writing by hand $(M=110.85, S D=36.68)$. However, females wrote significantly more words on the computer $(M=138.58, S D=51.61)$ than by hand $(M=112.33$, $S D=27.94)$.

\section{Correlation Between Number of Words and Power Imagery}

Correlation coefficients were computed between the number of words in each story and the amount of power imagery expressed by the subject. The correlations were $r(118)=.43, p<.01$, for the restaurant picture; $r(118)=$ $.28, p<.01$, for the military picture; $r(118)=.26, p<$ .01 , for the laboratory picture; and $r(118)=.23, p<.05$, for the bridge picture. The correlation between the number of words and the amount of power imagery expressed in the trapeze picture was not significant. Partial support for the final hypothesis was found.

\section{DISCUSSION}

The first major criticism of the TAT, its reported low internal consistency, can be challenged on two levels. First, we have shown that when the reliability of the TAT is computed on the basis of the numerical scores of the separate paragraphs, guided by four sets of questions, the reliability is much higher than previously reported. On a conceptual level, we believe that the TAT is a qualitatively different type of test, an implicit measure of motivation (McClelland et al., 1989), for which the assumptions of traditional test theory do not fully apply. The dynamics of action theory (Atkinson \& Birch, 1970) predicts that the stream of thought sampling (DeCharms, 1992) will necessarily be affected by competition with thoughts instigated by other motives (e.g., n Ach) and by the consummatory effect (decrease in expression of a tendency) caused by previous expressions of $n$ Pow. This means that the $\mathrm{n}$ Pow content of one story will be affected by a competing tendency to write about $\mathrm{n}$ Ach, for example, and that the expression of $n$ Pow in one story may decrease the likelihood of $n$ Pow's being expressed in the next story. These dynamics decrease the internal consistency of an implicit measure, such as the TAT. To hold a thought-sampling measure to the same psychometric requirements as those for a self-report measure, where the same question is asked several times with minor variations, is inappropriate.

Power imagery varied significantly across the pictures used, with the military picture eliciting the most $n$ Pow and the bridge picture eliciting the least $n$ Pow. The military picture is a strong cue for power, usually being in- terpreted as a picture of an officer directing his subordinates. Returning to the logic of the dynamics of action, we see little competition in this picture with other motives such as $\mathrm{n}$ Ach or $\mathrm{n}$ Aff (need for affiliation). On the other hand, the bridge picture often elicits stories rich with $\mathrm{n}$ Aff and sometimes stories with $\mathrm{n}$ Ach. Haber and Alpert (1958) found that the set of TAT pictures was more internally consistent when stronger cues were used. However, increasing internal consistency by choosing only strongly cued pictures might overpower individual differences in $n$ Pow. That is, in choosing picture cues, there will always be a tradeoff between using stronger cues that will decrease the competition with other motives and using weaker cues that are more diagnostic of high power motivation. (The person who writes a power story to the bridge picture must be very high in $n$ Pow.) The five pictures that we used produced a large enough dispersion of scores and satisfied our goal to get a distribution of scores that was fairly normal.

The sequential effect of expressing power imagery in one story on the strength of tendency to express power imagery in the next story was not evident in our data. When we compared the power imagery expressed in the second story by those subjects who expressed power imagery in the first story and those who did not, there was no significant difference between the two groups. The consummatory effects of expressing $n$ Pow, decreasing the probability of expressing $n$ Pow in the next story, would be counteracted by the tendency of those with high power motivation to express $\mathrm{n}$ Pow in all stories. Therefore, we do not believe that our design, with no independent measure of power motivation, provides an adequate test of the consummatory effects.

The fact that there were no differences in $n$ Pow between males and females does not appear to be a result of low power in the statistical tests. As the MANOVA table indicates, the error term in the analysis of gender and the two experimental manipulations (hand written vs. computer written and timed vs. untimed) was very small. That, plus the highly significant effect for the five pictures in the same analysis, argues that males and females were virtually the same in $\mathrm{n}$ Pow and that the lack of significance for gender was not due to excessive error variance. If one conceptualizes the TAT as a projective test (and not a thought-sampling exercise as proposed by DeCharms, 1992), the fact that four of our five pictures had both male and female characters in them may have contributed to both groups of subjects projecting the same amount of power into the stories.

The finding of no differences between hand-written and computer-written and between timed and untimed conditions, indicates that the TAT is reliable across various testing conditions. We did not standardize scores on the basis of the stories' length because we were interested in differences that might be related to word production as a result of whether or not the tests were written on the computer and whether or not the tests were timed. Again, we believe that the lack of a significant difference was 
not due to low power in the statistical tests. We would argue that researchers can gather TATs on the computer and not worry about the amount of $n$ Pow in the stories being affected by the mode of testing. This interpretation is consistent with other recent research, such as the findings of Webster and Compeau (1996) that responses to computerassisted questionnaires do not differ from those administered by paper and pencil, as long as the subject of the test does not refer to computers themselves.

The fact that subjects who were assigned the computer writing condition could not go back and change their stories in the output window once they had moved to the next set of questions can be seen as further support for the computer writing of TAT stories. McClelland et al. (1989) have characterized implicit motives, like those measured by the TAT, as arising from early childhood experiences. In contrast to self-attributed motives, which are subject to social norms, implicit motives "provide a more direct readout of motivational and emotional experiences" (p. 698). Less editing of stories can be seen as a way to increase their validity as a measure of these implicit motives, especially motives such as power that are viewed by some people as going against social norms.

The greater number of words produced in the untimed conditions was expected. However, the untimed subjects did not express more $n$ Pow. In both the hand-written and the computer-written conditions, the subjects often commented that they felt rushed in the timed conditions. We recommend that researchers consider testing subjects on the computer in the untimed condition, since this does not make any difference in the amount of power imagery in TAT stories and will also decrease the effect of typing speed on word production.

The greater number of words written by females was not surprising, but the interaction of gender and handwritten versus computer-written condition was not expected. Furthermore, the greater number of words produced by females in the computer-written condition cannot be accounted for by their greater typing ability. Subjects were asked to report their typing ability, and the modal response was "intermediate" for both males $(n=$ $42)$ and females $(n=41)$. The chi-square comparison between males and females was not significant $\left[\chi^{2}(2)=\right.$ $1.43, p=.49]$.

There was a significant correlation between number of words and $\mathbf{n}$ Pow in all the pictures except the trapeze picture. That is partly because the trapeze stories had the smallest number of words. Whereas many of the stories to the other four pictures were initially scored on the basis of Category 1 (forceful actions) or Category 3 (concern with reputation or position), a majority of the trapeze stories that were scored for $\mathbf{n}$ Pow were coded on the basis of Category 2 (arousing strong emotions in others). A common theme was risky maneuvers by the acrobats that resulted in the enthusiastic approval of the audience, a theme that could be expressed in fewer words. The restaurant stories, on the other hand, were coded on the basis of all three categories, including seduction (Category 1), extreme happiness (Category 2), and concern with status (Category 3). One difference between the trapeze cue and the restaurant cue is that subjects have a limited context for the trapeze situation and may find it more difficult to project themselves into that scene. On the other hand, they have numerous schemas (Markus, 1977) for restaurant situations, coming from their childhood and from their later experiences. This interpretation is strengthened by the interaction between pictures and the timed versus untimed conditions. You will recall that more $n$ Pow was written into restaurant stories in the untimed condition than in the timed condition, whereas more $\mathrm{n}$ Pow was written into the trapeze stories in the timed condition as opposed to the untimed condition. This makes sense only if you assume that subjects elaborate their restaurant stories when given additional time, thus increasing $n$ Pow. When subjects are writing the trapeze stories, the pressure of time increases their tendency to write stereotypic stories of winning praise from the audience, meeting the criterion for Category 2.

\section{CONCLUSIONS}

The present study should be replicated with the use of other motives. As noted earlier, achievement imagery might be increased by computer writing, and it is possible that computer writing might decrease the amount of affiliation or intimacy imagery in TAT stories. These possibilities should be explored. Future research should also focus on identifying the best pictures to be used in research on the various motives. Other tests have specific items; we argue that TAT measures of motives should have specific items in the form of pictures that together elicit a normal distribution of scores among subject populations.

We propose that a computer-based method of content analysis of the TAT will require interaction between a human coder and the computer screen. We do not believe that the complex level of coding necessary for the TAT, with interpretations of meaning and the coding of subcategories (see the example above), can be handled by a simple word-matching program. Rather, the computer coding system will have to allow the human coder to view the text, highlight significant phrases, and assign subcategories to those phrases. These highlighted phrases would be captured by the program, along with the subcategory codings. This would allow for quick comparisons of the codings of two independent coders and would help a third coder eliminate the discrepancies between coders. The numerical scores, by paragraph, would be transferred automatically to a data file, all of which are factors that would save time.

In conclusion, we believe that the TAT has an acceptable level of internal consistency when each story is viewed as a multi-item test. The absence of gender, hand-written versus computer-written, and timed versus untimed effects on power imagery argues that it is stable across males and females and across various presentation modes. 
The coding of TAT stories will always be time consuming if content validity is to be attained. However, we think that stories written on the computer will facilitate a computer-based approach to content coding, an approach that will not replace the human coder but will cut down on the time required for careful coding. If one wants an implicit measure of motives, a measure arising from early childhood experiences reflecting affective experiences, (McClelland et al., 1989), then the TAT and its rich verbal content are worth the time and trouble.

\section{REFERENCES}

ATKINSON, J. W. (Ed.) (1958). Motives in fantasy action and society Princeton, NJ: Van Nostrand.

ATKINSON, J. W. (1982). Motivation determinants of thematic apperception. In A. J. Stewart (Ed.), Motivation and society (pp. 3-40). San Francisco: Jossey-Bass.

AtKinson, J. W., \& BIRCH, D. (1970). The dynamics of action. New York: Wiley.

Atkinson, J. W., Bongort, K., \& Price L. H. (1977). Explorations using computer stimulation to comprehend TAT measurement of motivation. Motivation \& Emotion, 1, 1-27.

BANGERT-DROWNS, R. L. (1993). The word processor as an instructional tool: A meta-analysis of word processing in writing instruction. Review of Educational Research, 63, 69-93.

Brown, J. S., McDonald, J. L., Brown, T. L., \& Carr, T. H. (1988). Adapting to processing demands in discourse production: The case of handwriting. Journal of Experimental Psychology: Human Perception \& Performance, 14, 45-59.

DeCharms, R. (1992). Personal causation and the origin concept. In C. P. Smith (Ed.), Motivation and personality: Handbook of thematic content analysis (pp. 325-333). New York: Cambridge University Press.

ENTWISLE, D. R. (1972). To dispel fantasies about fantasy-based measures of achievement motivation. Psychological Bulletin, 77, 377-391.

FINEMAN, S. (1977). The achievement motive construct and its measurement: Where are we now? British Journal of Psychology, 68, 1-22.

HAAS, C. (1989). How the writing medium shapes the writing process: Effects of word processing on planning. Research in the Teaching of English, 23, 181-207.

HABER, R. N., \& ALPERT, R. (1958). The role of situation and picture cues in projective measurement of the achievement motive. In J. W. Atkinson (Ed.), Motives in fantasy, action and society (pp. 644-663). Princeton, NJ: Van Nostrand.

Hawisher, G. E. (1986). Studies in word processing. Computers \& Composition, 4, 6-31.

HAWISHER, G. E. (1988). Research update: Writing and word processing. Computers \& Composition, 6, 7-27.

JENSEN, R. (1959). The reliability of projective techniques: Review of the literature. Acta Psychologica, 16, 108-136.

KellogG, R. T., \& Mueller, S. (1993). Performance amplification and process restructuring in computer-based writing. International Journal of Man-Machine Studies, 39, 33-49.
Markus, H. (1977). Self-schemata and processing information about the self. Journal of Personality \& Social Psychology, 35, 63-78.

McClelland, D. C. (1975). Power: The inner experience. New York: Irvington Publishers.

MCClelland, D. C. (1985). Human motivation. Glenview, IL: Scott, Foresman.

McClelland, D. C., Atkinson, J. W., Clark, R. A., \& Lowell, E. L. (1953). The achievement motive. New York: Appleton-Century-Crofts.

McClelland, D. C., Koestner, R., \& Weinberger, J. (1989). How do self-attributed and implicit motives differ? Psychological Review, 96, 690-702.

Morgan, C. D., \& Murray, H. A. (1935). A method for investigating fantasies. Archives of Neurology \& Psychiarry, 34, 280-306.

MurRay, H. A. (1938). Explorations in personality. New York: Oxford University Press.

Murstein, B. I. (1965). Reliability. In B. I. Murstein (Ed.), Handbook of projective techniques (pp. 189-218). New York: Basic Books.

NicHOLS, R. G. (1986). Word processing and basic writers. Journal of Basic Writing, 5, 81-97.

Nunnally, J. C. (1978). Psychometric theory (2nd ed.). New York: McGraw-Hill.

RiNDLER, S. E. (1979). Pitfalls in assessing test speededness. Journal of Educational Measurement, 16, 261-270.

Rosenbluth, G. S., \& Reed, W. M. (1992). The effects of writingprocess-based instruction and word processing on remedial and accelerated 11 th graders. Computers in Human Behavior, 8, 71-95.

Smith, C. P. (1992). Reliability issues. In C. P. Smith (Ed.), Motivation and personality: Handbook of thematic content analysis (pp. 126139). New York: Cambridge University Press.

VANE, J. A. (1981). The Thematic Apperception Test: A review. Clinical Psychology Review, 1, 319-336.

WeBster, J., \& Compead, D. (1996). Computer-assisted versus paperand-pencil administration of questionnaires. Behavior Research Methods, Instruments, \& Computers, 28, 567-576.

Winter, D. G. (1973). The power motive. New York: Free Press.

WINTER, D. G. (1992). A revised scoring system for the power motive. In C. P. Smith (Ed.), Motivation and personality: Handbook of thematic content analysis (pp. 311-324). New York: Cambridge University Press.

\section{NOTES}

1. We wish to distinguish the thematic apperception method we use from the set of 20 cards developed by Murray and used in clinical practice and research. Although several of the studies to which we refer were conducted with pictures from the Murray TAT, much motivational research, including our own, uses a different set of pictures, which are reproduced in Atkinson (1958), Winter (1973), McClelland (1975), and Smith (1992).

2. We thank an anonymous reviewer for this suggestion.

(Manuscript received January 14, 1997; revision accepted for publication May 21, 1997.) 